\title{
Pessoas, manatins e o ambiente aquático na América moderna: confluência e divergência nas interações históricas entre humanos e animais
}

People, Manatees and the Aquatic Environment in Early

Modern Americas: Confluence and Divergence in the Historical Relationships Between Humans and Animals

Cristina Brito *, 1

\section{Resumo}

Com uma distribuição geográfica histórica alargada em zonas costeiras, ambientes de transição e fluviais do Oceano Atlântico tropical, o manatim (manati das Índias Ocidentais, peixe-boi ou iguaragua do Brasil colonial) era bastante valorizado. As fontes documentais e iconográficas dos séculos XVI e XVII mostram-nos que era usado como alimento, para fins medicinais, para produzir utensílios ou como animal de estimação, mas seu valor económico e simbólico foi igualmente dominante. A sobre-exploração contínua conduziu ao desaparecimento de muitas populações de manatins, os quais hoje enfrentam o risco de extinção. Pretendemos explorar do ponto de vista da história ambiental marinha o significado pragmático $\mathrm{e}$ simbólico dos manatins numa ligação próxima aos valores atribuídos aos rios e cursos de água. Esperamos também

\begin{abstract}
The manatee (manati of the West Indies, also called manatim or iguaragua in colonial Brazil) was highly valued and presented a broad historical geographic distribution in coastal, transitional and fluvial areas of the tropical Atlantic Ocean. Documental and iconographic sources of the $16^{\text {th }}$ and $17^{\text {th }}$ centuries show us that it was used as food and for medicinal purposes, to manufacture tools or even as a pet. Moreover, its economic and symbolic value was equally relevant. Continued overexploitation led to the disappearance of many populations of manatees, which are currently at the brinck of extinction. We will explore, from the point of view of marine environmental history, the pragmatic and symbolic meaning of the manatee in close connection to the importance given to rivers and watercourses. We also expect to contribute to
\end{abstract}

\footnotetext{
* Universidade Nova de Lisboa, Faculdade de Ciências Sociais e Humanas, Centro de Humanidades (CHAM), Lisboa, Portugal. cbrito@fcsh.unl.pt <http://orcid.org/0000-0001-7895-0784>
} 
contribuir para colocar manatins e o seu ecossistema no centro de uma discussão sobre contextos e interações ambientais e socioculturais das sociedades indígenas e coloniais nas Américas do período moderno.

Palavras-chave: história ambiental marinha; humanos e não humanos; ecossistemas fluviais; percepções na época moderna. place manatees and their ecosystem at the center of the discussion about the environmental and sociocultural contexts and interactions of indigenous and colonial societies in the Americas of the modern period.

Keywords: marine environmental history; humans and non-humans; riverine ecosystems; early modern age perceptions.

Rivers originate in one country, flow through others, and join the ocean. [...] Animals walk past, fish swim by, and birds fly over customs lines and immigration offices, military check points and border patrols. Nature's web defies containment. [...] "Saving nature" means taking a step away from ideologies of conquest. But it is all too easy to reproduce the patterns of the past. C.S. Lewis presciently wrote of how some men use nature as an instrument of power over other men. [...] Boundaries [do have] consequences for the lines between humans and the natural world. The histories we write have to face the challenges unfolding in the world we live in.

(Rangarajan, 2011, p. 27-30)

Os rios representam vida e destruição. Estão presentes em quase todas as paisagens e momentos da humanidade, seja física ou espiritualmente, e exercem enorme influência sobre as pessoas e sociedades (Mauch; Zeller, 2008). Os rios desafiam todas as fronteiras e todos os confinamentos, traçam o seu próprio caminho na história humana e na história dos seus ambientes. Mas apenas em teoria, porque os rios são um dos ambientes naturais mais sujeitos a constrangimentos físicos, barreiras e alterações (Mauch; Zeller, 2008). Talvez sejam o mais humanizado de todos os sistemas naturais. Os sistemas fluviais apresentam, em termos ambientais, conteúdo geomorfológico diversificado e elevada biodiversidade associada. Vários tipos de habitats fazem parte dos sistemas fluviais, desde a zona de nascente às águas correntes e paradas, planícies aluviais, margens e vegetação ripícola, estuários, sapais e mangais, lagoas e uma grande diversidade de zonas costeiras de diferentes morfologias. Em termos antropogénicos, encontramos associados aos rios diversas obras de 
engenharia para fins energéticos, agrícolas e de transportes, como diques e barragens, condutas, canais e eclusas, viadutos ou pontes, para além do uso do leito do rio como meio de transporte de pessoas e mercadorias. Essas estruturas humanas limitam, alteram e condicionam os leitos dos rios e os habitats que lhes estão associados, afetando direta e indiretamente todas as formas de vida fluviais e costeiras (e.g. Coates, 2013). Por exemplo, em determinadas situações, a construção de barragens - que inevitavelmente conduz à retenção de sedimentos a montante - e a extração de areia para fins comerciais em diversos troços de um rio podem ter repercussões negativas na faixa costeira a jusante: erosão (e.g. National Research Council, 1990; Ferreira; Matias, 2013). Em consequência, essas estruturas têm influência nefasta nos habitats salobros e marinhos (e.g. Mangor, 2018).

Ainda assim, os rios correm, movimentam-se, nascem e desaguam, são zonas de contacto entre sua nascente e foz que, ao criar ligações entre esses mesmos espaços, também criam barreiras físicas entre territórios naturais ou humanizados. São também sistemas que ligam zonas terrestres - áreas interiores dos espaços continentais ou insulares - a zonas costeiras, desaguando em mares e oceanos. Os rios são ainda fonte de vida, de água e de alimento, tanto para pessoas como para animais. Muitos dos seus troços constituem verdadeiras zonas de agregação de fauna terrestre e constituem habitat natural de inúmeras espécies de flora e fauna aquática ou de características anfíbias. Muitos desses ambientes ribeirinhos são ainda zonas propícias à agregação de comunidades humanas que aí estabelecem com facilidade áreas preferenciais de habitação, de caça e pesca, ou de trocas comerciais. Os rios fornecem muitos dos recursos necessários à sobrevivência da espécie humana (e.g. Coates, 2013, p. 7-31). Em muitas sociedades, os rios não são apenas um local de criação de vida, tal como todo o ambiente aquático o é, mas também um local de passagem, de transporte e de continuidade. Globalmente, grandes civilizações se estabeleceram e desenvolveram nas bacias fluviais ou desembocaduras dos grandes rios do planeta. E estes serviram também de estrada para grandes conquistas, para o desenvolvimento e distribuição de tecnologia, para o transporte de pessoas, mercadorias, ideias e conhecimento (McCully, 2001). Os rios simbolizam todo o poder da natureza, mas também o poder e riqueza das pessoas, e todas as possibilidades de reverência, inspiração e recreação (Coates, 2013, p. 7-31).

Os rios são símbolos. As suas águas geradoras de vida e fertilidade são igualmente criadoras de mitos e lendas. As grandes bacias hidrográficas mundiais fertilizam terras e, desde os alvores da história, delas florescem as 
divindades que controlam esses espaços e que garantem a abundância (Blackbourn, 2008a, 2008b). São inúmeras, e cruzam tempo e sociedades, as divindades - normalmente femininas - associadas aos rios, desde a mais pequena e singela ninfa aquática à mais poderosa mãe d'água. Não é por acaso que, em muitas partes do mundo, os rios são apelidados de "Mãe" (McCully, 2001). Mas foram também para muitas culturas locais míticos e palco de rituais de passagem onde os guerreiros - homens - depositavam as suas armas em honra das divindades que habitavam as águas (Bradley, 1990). A dualidade simbólica está desde sempre presente. Considerando ainda que as suas águas se movimentam, que criam um percurso, muitas vezes os rios indicam um caminho a percorrer física e geograficamente, mas também um caminho espiritual e simbólico entre o princípio (a nascente) e o fim (a foz). Esse simbolismo do percurso, das diferentes etapas da vida, reflete os próprios ritmos da natureza e das estações e, consequentemente, os ritmos da vida humana entre os momentos de nascimento e de morte.

Ao unir num mesmo elemento a realidade natural e a humana, os rios são, em muitas culturas espalhadas pelo globo, considerados partes vivas e constituintes de um sistema único e integrado humano-natureza. São vários os animais dos rios, ou relacionados com os ambientes fluviais e de transição entre o rio e o mar, que têm associado um simbolismo próprio e fazem parte dos mitos, tradições e práticas rituais e simbólicas de muitas culturas humanas (Loveland, 1976). Por esse motivo, ou porque existem mais historiadores a tratar temas ambientais, encontramos cada vez mais investigadores de história ambiental e de outras disciplinas das humanidades a estudar os rios em toda a sua multiplicidade (e.g. Worster, 1992; Blackbourn, 2008a; Mauch; Zeller, 2008). Os rios são hoje temas centrais em muitas problemáticas da história ambiental, da história cultural, da etnologia e da antropologia. Permitem abordar aspetos socioeconómicos das comunidades ribeirinhas, questões políticas dos territórios por onde passam, questões ambientais relacionadas com alterações ao longo do tempo, usos e práticas, impactos humanos, conservação de espécies e habitats, entre muitas outras, e ainda aspetos mitológicos, simbólicos e religiosos. É possível escrever a biografia de um rio, assim como a história da sua (i)materialidade (Blackbourn, 2008a), e ainda dos vários elementos naturais que o compõem - incluindo o mundo humano e o não humano e as suas intricadas interações.

Neste trabalho, pretendemos analisar a presença dos rios e dos animais aquáticos na vida das sociedades da América colonial. Para tal, iremos percorrer um caminho ondulando entre as confluências e divergências do contacto 
humano com o rio e com alguns dos seus seres vivos, usando exemplos da relação histórica - real e simbólica - entre pessoas e manatins na América Central e do Sul, da época moderna. Tal como os rios fluem, e as suas águas ora se encontram, ora se afastam, também as relações entre pessoas e esses animais aquáticos flutuam e divergem, como veremos pelos exemplos que serão aqui explorados. Na verdade, os animais são, como o próprio rio, metáforas para os ritmos naturais e sociais de ordem e desordem. Muitos relacionam-se simbolicamente com o mundo natural ruidoso e disruptivo, mas alguns - como o manatim - são também, em algumas sociedades indígenas, desde sempre associados a um mundo cultural pleno de calma, silêncio, ordem social e solidariedade, e ainda ligados aos recursos da água e à prosperidade do ambiente (e.g. Durand, 1950; Loveland, 1976). Por essas razões, o manatim é um elemento natural apropriado e um bom caso de estudo para discutir os múltiplos valores culturais e naturais tipicamente associados aos rios e aos seus animais. Usando fontes históricas (escritas e icnográficas) para as ilhas das Caraíbas e para zonas ribeirinhas da América Central e do Sul, ao longo dos séculos XVI e XVII, será possível debater o valor do rio enquanto elemento da paisagem e da vida diária e ainda reposicionar os manatins no seu contexto ambiental e histórico-cultural das sociedades indígenas e coloniais da época.

\section{As AmÉricAs, os RIOS E OS MANATINS}

Mar Oceano e as terras que o limitam, nos alvores do período moderno. Nessa época, fosse na Europa, nas ilhas Atlânticas, na costa Ocidental Africana ou nas costas das Américas, as pessoas individualmente ou em grupo - enquanto sociedade - reagiam de formas muito semelhantes a determinados tipos de animais marinhos ou aquáticos com os quais lidavam diariamente ou ocasionalmente. Por exemplo, quase todas as sociedades humanas reagiam - e ainda reagem - com medo à proximidade de grandes tubarões. Esses grandes peixes eram tipicamente considerados perigosos, e deles as pessoas preferiam manter distância. ${ }^{2}$ Mas eram também comumente pescados e consumidos um pouco por todo o mundo, e ainda caçados simplesmente por diversão ou medo. No entanto, as pessoas não tinham conhecimento da forma como outras sociedades, noutras partes do mundo, lidavam com esses animais. Não tinham como saber, já que não sabiam da existência dessas outras sociedades, embora o conceito de existirem pessoas com culturas distintas não fosse uma novidade em algumas partes do mundo. Nem tampouco sabiam da existência de toda uma panóplia de animais endémicos ou típicos de determinadas regiões bio- 
geográficas que despertavam diferentes sentimentos e (re)ações nas pessoas.

Américas, a partir dos finais do século XV. Foi esse um dos momentos na história humana em que diferentes sociedades entraram em contacto umas com as outras pela primeira vez. Num espaço e num tempo em que povos com diferentes formas de vida, diferentes visões e conhecimento do mundo, diferentes modos de contactar com a realidade natural em seu redor, se encontraram. Nessa zona do mundo, à chegada dos primeiros Europeus, os ecossistemas costeiros e aquáticos interiores - à semelhança de determinados ecossistemas terrestres - encontravam-se parcialmente alterados pelos ocupantes nativos das terras, os quais eram dependentes da exploração de determinados recursos. Essa era uma realidade tanto para ambientes terrestres como para os aquáticos, tanto para os recursos florísticos como para os faunísticos. No entanto, a chegada dos exploradores e colonizadores europeus veio alterar drasticamente e de forma irreversível a escala e a intensidade com que esses mesmos ambientes e recursos naturais eram explorados e usados. Muitas das atividades de exploração dos recursos aquáticos foram durante anos, aliás durante séculos, sustentadas, pelas necessidades de pescadores e caçadores locais, exploradores e mercadores estrangeiros, mas também pela biodiversidade e produtividade natural dos ecossistemas. Tal como muitas outras explorações na América colonial, essas atividades foram sustentadas, mas nunca foram sustentáveis (e.g. Cabral, 2015, p. 92-93). Tomemos, então, como exemplo os manatins. Vários autores que escreveram sobre a história natural e cultural dos manatins durante o século XX (e.g. Durand, 1950) referem que Cristóvão Colombo foi o primeiro europeu a descrever esses animais tropicais. Durand (1950) no seu "Ocaso de Sirenas" descreve textualmente as palavras de Colombo quando, no dia 9 de janeiro de 1493, este se cruzou com três formas de cor parda, diferentes de qualquer outro peixe conhecido, que emergiram à superfície das águas e que ele reconheceu como as sereias que já teria previamente encontrado nas costas da Guiné. ${ }^{3}$ Não sendo tão bonitos no rosto como seria de esperar, o Almirante supôs, por essa razão, tratar-se de machos. Seriam, na verdade, manatins, esses "pomposos anfíbios" (Durand, 1950, p. 13-14). De facto, os manatins seriam já conhecidos pelos europeus nas costas ocidentais de África, outrora uma região geográfica de abundante ocupação por esses animais. Da mesma forma, os dugongos - Dugong dugong -, que têm apenas uma distribuição no Oceano Índico e no Indo-Pacífico, seriam igualmente conhecidos por via dos contactos com a Ásia.

As três espécies de manatins habitam águas tropicais costeiras e interiores de África, América Central e do Sul (Figura 1): manatim Africano (Trichechus 


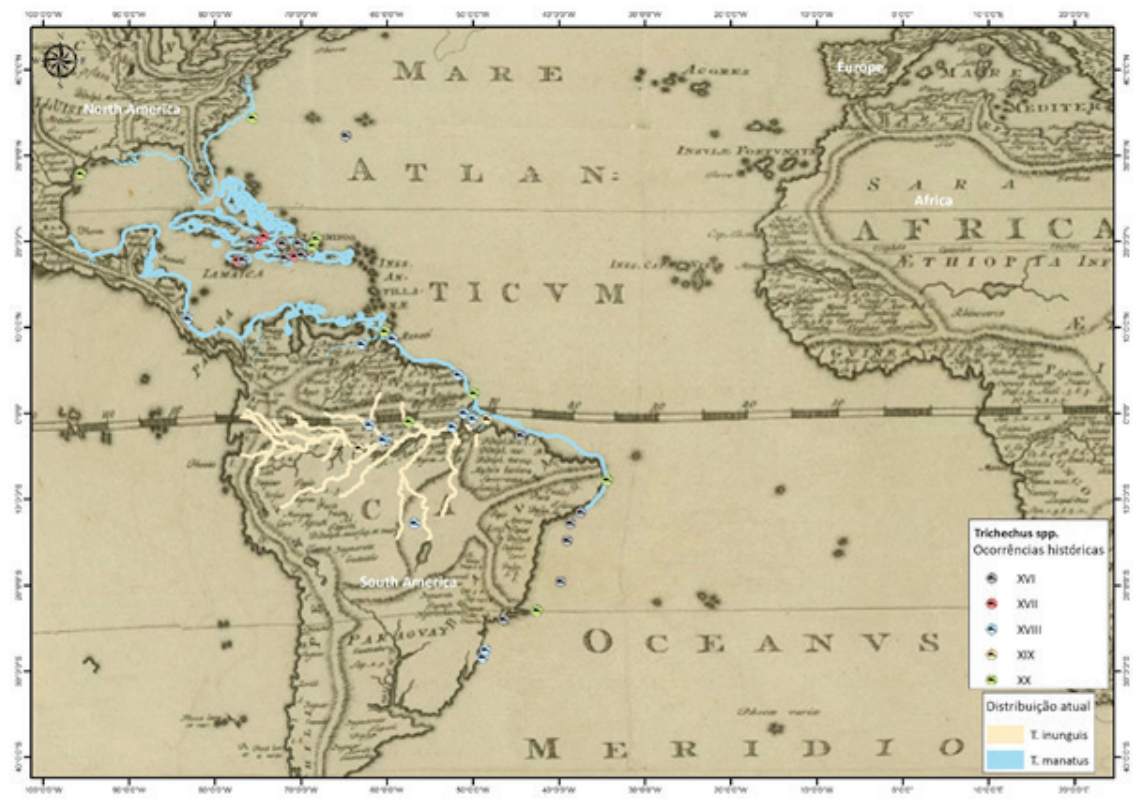

Figura 1 - Distribuição atual e histórica de T. manatus e T. inunguis. As zonas de distribuição atual foram obtidas com base na shapefile da distribuição de espécies do site da IUCN (http://www.iucnredlist.org/technical-documents/red-list-training/ iucnspatialresources) sobre mapa de Zimmermann (1777). Esse mapa foi georreferenciado usando o software ESRI ARCGIS 10.5.1, mediante definição de pontos de controlo comuns no mapa sobre uma base ortorretificada e georreferenciada. A ocorrência histórica de manatins nas Américas indica uma visão macro da distribuição das espécies no período em causa (séculos XVI-XIX), obtida com base na leitura das fontes históricas e não de uma posição georreferenciada real.

senegalensis), manatim das Índias Ocidentais (Trichechus manatus) e manatim do Amazonas (Trichechus inunguis). De semelhante aparência exterior, apenas a sua distribuição geográfica ajuda a distinguir qual a espécie em causa. ${ }^{4}$ São historicamente conhecidos por peixe-mulher ou mami-wata na África Ocidental, manati nas Caraíbas e peixe-boi ou iguaragua na América do Sul. Em todas essas regiões teriam tido - e, nalguns casos, continuam a ter - valor económico e simbólico para as sociedades locais. Como resultado de uma exploração excessiva e continuada, assim como pela redução na disponibilidade e qualidade ambiental dos seus habitats, a distribuição geográfica atual dos manatins encontra-se bastante reduzida e fragmentada, e todas as espécies de manatins se encontram ameaçadas de extinção. ${ }^{5}$ Embora os manatins (e 
também os dugongos) - animais grandes e com vida gregária - sejam os únicos mamíferos aquáticos herbívoros e estejam frequentemente à superfície da água, são também bastante elusivos e de difícil observação na natureza. Foi Lineu, nos finais do século XVIII, que descreveu a Ordem Sirenia para a ciência, de forma a nela incluir os manatins (género Trichechus), mas desde os alvores do século XVI são frequentemente encontrados e descritos por autores portugueses e castelhanos nas Américas.

As descrições de manatins são recorrentes, muitas vezes semelhantes - se não mesmo cópias entre autores -, e o interesse ao longo dos séculos parece ser o mesmo: dar a conhecer o valor naturalista e económico de animais exóticos e desconhecidos na Europa. ${ }^{6}$ Sendo difícil trazer o animal do seu habitat natural - vivo ou um espécime preservado -, a palavra e a ilustração servem de substituição e de mostruário para o público renascentista ávido de novidades (e.g. Leite, 2014; Papavero; Teixeira, 2014; Brito, 2018).

Há um certo peixe, a que chamamos boi marinho, os Índios o denominam de iguaraguá, frequente na Capitania do Espírito Santo e em outras localidades para o Norte, onde o frio ou não é tão rigoroso [...] alimenta-se de ervas como o indicam as gramas mastigadas presas nas rochas banhadas por mangues. Excede ao boi na corpulência; é coberto de uma pele dura, assemelhando-se na cor à do elefante; tem junto aos peitos uns como dois braços com que nada; e embaixo deles tetas com que aleita os próprios filhos; tem a boca inteiramente semelhante à do boi. É excelente pera comer-se, não saberias porém discernir se deve ser considerado como carne ou antes como peixe; da sua gordura, que está inerente à pele e mormente em torno da cauda levada ao fogo faz-se um môlho, que pode bem comparar-se à manteiga e não sei se a excederá; o seu óleo serve pera temperar todas as comidas: todo o seu corpo é cheio de ossos sólidos e duríssimos, tais que podem fazer as vezes de marfim. (Anchieta, 1946, p. 11-12)

Vejamos ainda outra descrição, agora para as chamadas Índias Ocidentais (Culcs-de-sac, Ilha de S. Bartolomeu) já na transição do século XVII para o século XVIII:

Eu cheguei lá a tempo de ver tirar à terra uma Lamentin fêmea que estes negros tinham arpoado. Eu tinha ouvido muitas coisas sobre o manatim, mas nunca tinha visto nenhum, porque ele se tornou bastante raro desde que a praia é habitada. Este peixe procura os lugares onde existem rios porque ele vem beber água doce uma vez ou duas cada dia, depois de ter comido uma certa erva que cresce no fundo do mar [...] Os Espanhóis chamam-lhe Manate ou Manati, que quer 
dizer, peixe que tem mãos, enquanto nós chamamos Lamentin. Nós poderíamos, parece-me, chamar-lhe vaca marinha $[\ldots]$ os nossos bucaneiros muitas vezes não têm outro recurso para viver que a pesca do manatim, que me asseguram que nem eles nem os Índios (de l'Ithme de Darien) que são os melhores pescadores do mundo, viram o manatim em terra. [...] Considerou-se que este manatim pesava oitocentos quilos. Eu não o pesei, mas à vista penso que não estariam muito longe da verdade. Os pescadores também tinham levado o seu pequeno, tinha cerca de um metro de comprimento; nós o comemos ao jantar. (Labat, 1722, p. 200-203)

A observação empírica da fauna local torna-se cada vez mais uma necessidade para explicar e justificar um mundo natural ainda pouco conhecido (Brito, 2018). Apesar do claro interesse vernacular, a sua entrada nos anais da ciência foi tardia, e apenas alguns entre os naturalistas enciclopedistas, como Ulisses Aldrovandi, os incluíram nos seus tratados (e.g. Papavero; Teixeira, 2014; Brito, 2018).Os manatins continuaram a ser descritos mesmo quando, a partir do século XVIII, começam a surgir indicações de que a sua abundância diminui. $^{7}$

\section{O VALIOSO PEIXE-BOI E O NOBRE MANATIM, OU, OS DOIS LADOS DO MESMO ANIMAL}

Em todos os rios e zonas costeiras da América Central e do Sul os manatins foram, historicamente, usados como recurso de grande valor para as populações indígenas. Eram caçados usando diferentes técnicas, conforme a região geográfica e a comunidade indígena, provavelmente também em função do habitat e do tamanho de cada indivíduo, recorrendo a arpões (Figura 2), redes, e até usando métodos menos conhecidos como as rémoras (e.g. Gudger, 1919, p. 301-311; Durand, 1950, p. 79-84). A chegada dos primeiros europeus às ilhas e costas das Américas veio aumentar o impacto das populações humanas sobre esses animais. Veio, igualmente, reiterar a perceção europeia de que o rio era um local de nascimento de vida, de diversidade e abundância e, nestas terras, aparentemente de uma abundância sem fim. Era um ambiente que estava à disposição de quem o tomasse e que, por ser inesgotável, poderia - e deveria - ser continuamente explorado. Os rios, cursos de água e lagoas, para além de servirem de entrada e saída dos territórios a explorar, foram rapidamente apropriados em todas as suas valências. 


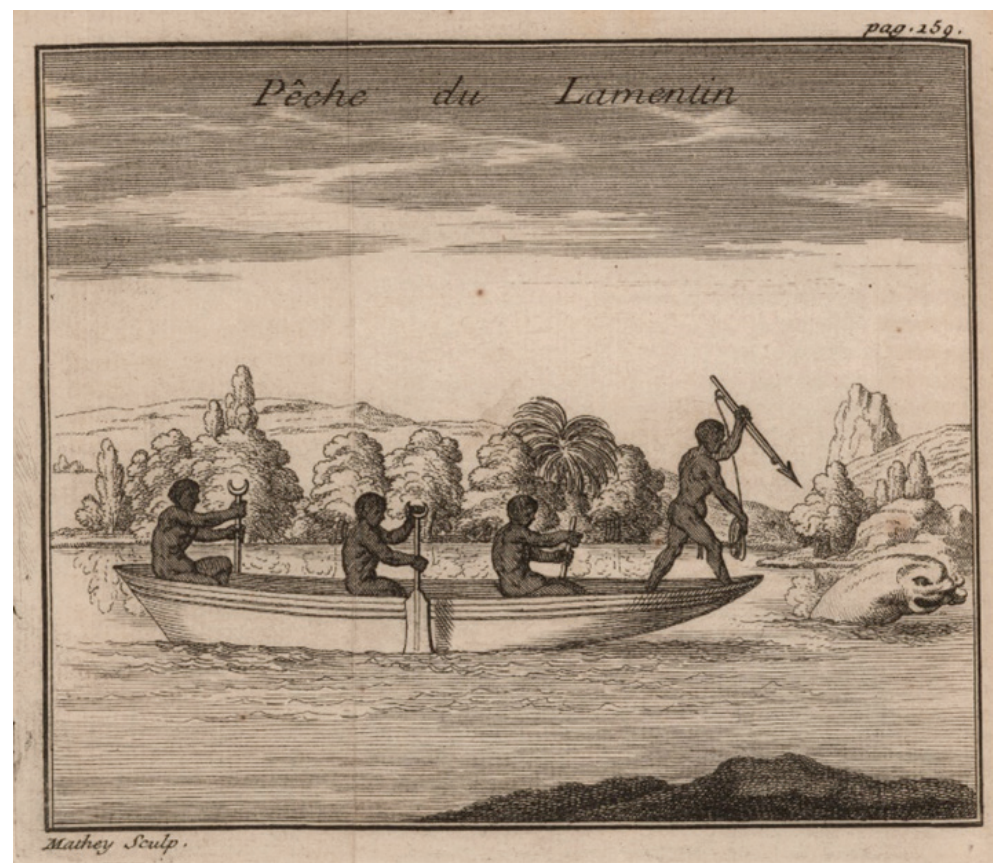

Figura 2 - A pesca do manatim na Guiana Francesa (século XVIII), ilustrada na obra de Barrere (1743). Esta ilustração mostra uma técnica de caça dos manatins recorrendo ao uso de arpão manual, a qual era usada por indígenas de diferentes regiões das Américas.

Os manatins surgem descritos, e ocasionalmente ilustrados, nos tratados de história natural e história geral, nas cartas e relações de missionários, de quase todos os autores que à época escreveram sobre a América colonial, tanto a portuguesa como a castelhana. $\mathrm{O}$ seu aspeto geral, o seu tamanho, o facto de serem "peixes" que na verdade respiravam ar e tinham (e amamentavam) crias, os seus comportamentos, o seu habitat, a forma de os capturar, de os cozinhar, de obter e consumir a pedra do cérebro para curar os males de pedra dos rins, e muitos outros aspetos são repetidos vezes sem conta. Alguns autores escrevem com base na observação empírica, ou com base nos relatos de quem os viu com os próprios olhos - fossem indígenas ou europeus -, enquanto outros traduzem e copiam escritos anteriores (e.g. Camenietzki; Zeron, 2000; Leite, 2014; Brito, 2018). Assim, a informação sobre animais e ambiente constrói-se paulatinamente.

Há lá [nas Antilhas] um peixe que se chama monatim; é grande e de coiro, tem a cabeça e rosto de vaca, e também na carne parece muito a ela. [...] É muito 
saboroso; tem umas pedras na cabeça que são proveitosas para a dor de pedra, e a fêmea tem tetas nos peitos com que cria os filhos que nascem vivos. (Galvão, [1573]1980, p.41)

Carvajal (1504-1584) descreve na sua "Descoberta da Amazónia” como os manatins eram presenteados aos europeus que os aceitavam em troca de outros produtos. À medida que a sua expedição avançava pelo rio Maranhão, "todos os dias, os Índios vinham e traziam o que comer, como manatins e tartarugas, assim como outros tipos de peixes [propriamente ditos] em troca de bens que o Capitão lhes dava"; na verdade, "todo o território providenciava com sustento, comida que consistia em manatins e peixe...” (Heaton, 1934, p. 416-419). Os recém-chegados europeus usavam e consumiam a carne de manatim com mais ou menos escrúpulos, ${ }^{8}$ mas rapidamente se aperceberam do valor desse animal, e os colonos passaram a usá-lo como um alimento comum (Veríssimo, 1970, p. 138). Também Cristóvão Acunha, ao referir-se aos peixes e às mais antigas pescarias do Amazonas, mencionava que se apanhavam peixes às mãos-cheias e que esse rio estava pleno de todo tipo de pescarias. Diz ainda que fazia parte dos hábitos alimentares dos indígenas e que "é o rei deste pescado, povoa todo o rio desde os seus princípios até que desagua no mar, no gosto só pelo nome é peixe, porque não há quem o coma que o não tenha por sazonada carne" (Veríssimo, 1970, p. 131). Muito facilmente, pela sua abundância e facilidade na captura, ou pela observação e apropriação dos usos locais, o manatim se torna um alimento predileto dos europeus nas Américas nos séculos XVI e XVII. Dizia Vasconcellos (1668, p. 36 e 280), para o Brasil colonial, "[que era] mui especial de tão inumerável quantidade de peixes boyes, \& tartarugas, que podiam aqueles moradores fazer tamanhos montes deles, \& delas" e que eram "os peixes boys mui ordinarios: cozem-se a maneira de carne, com couves ou arroz; \& podem enganar aos que o não sabem, parecendo-lhes vaca na vista, \& no sabor". Labat (1722, p. 206-207) referia na sua longa e detalhada descrição desse animal que "a gordura do manatim é muito boa; reduz-se facilmente a óleo que nunca rance e que pode ser empregue em diversos usos".

O animal fazia já parte da lista de alimentos de alta qualidade, cujos produtos eram usados para diversos fins, incluindo medicinais. Era também utilizado para outros propósitos; a pele de manatim era dura e de boa qualidade e usada para fazer escudos que serviam às populações indígenas em momentos de guerra. Os Europeus rapidamente os incorporaram como objeto corrente e os passaram a usar nas lutas contra os povos locais ou contra outros que viessem de fora (Heaton, 1934, p. 190, 319; Veríssimo, 1970, p. 131). 
O manatim não era apenas grande, útil e valioso, era também magnífico. Gómara o inscreve nos anais da história de Matto e do seu "dono", o cacique Caramatexi, chefe tribal dos Taíno. ${ }^{9}$

Manati é um peixe que não é do nosso mar, mas forma-se no mar e nos rios. [...] É capturado, no entanto, apenas nos bancos dos rios, ou no meio das ervas: também é apanhado com redes quando é pequeno. O Cacique Caramatexi uma vez capturou um muito pequeno, e criou-o durante vinte e seis anos num lago chamado Guainabo, onde ele viveu. Este animal cresceu tão doce e amigável que o podíamos tomar por um dos golfinhos de quem os Antigos deram tantas notícias. Ele vinha à beira [do lago] quando era chamado por Matto, o que significa na língua Índia Magnífico [ou Nobre]. Vinha fora de água para comer em casa, ficava na beira do lago com as suas crias, e aparentava ter prazer quando ouvia alguém cantar, permitia que subissem [às suas costas] e transportava as pessoas de um lado ao outro do lago sem os deixar cair na água, ele era um grande passatempo para os Índios. Um Espanhol a viajar, querendo saber se ele tinha a pele tão dura como se dizia, chamou Matto, Matto, e quando ele se aproximou deu-lhe uma estocada que não foi boa para ele, ainda que não tenha entrado nele, e essa era a razão porque ele não vinha fora de água quando via homens barbudos e vestidos como os Cristãos, podíamos chamá-lo mas era em vão. (Gómara, 1605, p. 41, 41v, 42)

Há toda uma sugestão poética nesta história, segundo a qual Matto torna-se simbólico para a história de um império: "[es] el más calificado testigo que, en nombre de la fauna marina, vió y convivió aquellos sucesos decisivos para la humanidade: el hallazgo y la conquista de América" (Durand, 1950, p. 40-41).

Na obra de Philoponus (1621, p. 59-60) surge uma ilustração do manatim de Gómara e a menção de que o Rei da ilha tinha um grande peixe, ou Baleia, chamado Manatem, que tem cabeça de boi, olhos pequenos, é coberto de couro e tem poucos pelos. Na imagem sobressai a evidência do poder imperialista sobre a natureza tropical e sobre os seus habitantes, mas também duma relação de dualidade que as pessoas, em geral, têm com os animais do seu meio circundante. Nessa ilustração (Figura 3) vemos em primeiro plano Matto a transportar as pessoas no lago, mas no fundo vislumbramos outra embarcação com dois caçadores/pescadores indígenas que caçam uma tartaruga e outro grande animal marinho - que não sabemos dizer com clareza se é um peixe, um cetáceo, ou mesmo outro manatim. Na margem direita homens em trajes europeus observam enquanto outro (um jovem, talvez) empenha um arco e flecha na 
direção de Matto ao lado de um homem indígena também armado de arco e flecha, mas com esta desarmada.

Neste trabalho, consideramos que esse manatim - tenha ou não existido conforme o descrevem ${ }^{10}$ - é simbólico para a história de um ecossistema natural e das relações entre pessoas e animais. Uma relação paradoxal de apreciação estética e emocional, e de uso utilitário e comercial, a qual não encontra facilmente um ponto de equilíbrio.

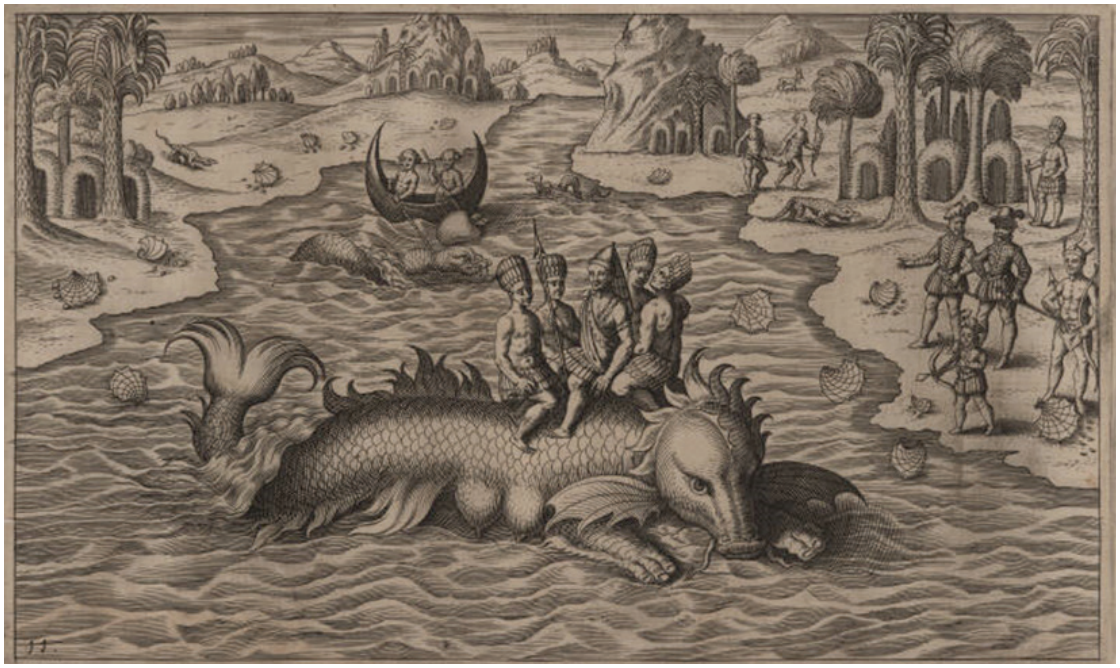

Figura 3 - Representação, na obra de Philoponus (1621), da história de Gómara sobre o manatim domesticado pelo cacique Caramatexi, que transportava membros da tribo entre as duas margens da lagoa; numa das margens, europeus observam a cena.

\section{RELAÇÕES HISTÓRICAS ENTRE HUMANOS E O MUNDO NÃO HUMANO}

Assim aconteceu que o Rio Hatibonico cresceu tanto que saiu das suas margens e entrou no Lago Guainabo, o que deu ao bom manatim Matto [uma oportunidade] de se retirar para o mar de onde tinha vindo, o que deixou Caramatexi e seus vassalos muito infelizes.

(Gómara, 2008, p. 68)

Caramatexi, por muito que o desejasse, não conseguiu manter o manatim de estimação para sempre na lagoa sob a sua alçada. A natureza sobrepôs-se à 
vontade do cacique e o manatim regressou ao seu ambiente natural. Como já mencionado, essa história surge na obra de Gómara que, para descrever algumas das características e virtudes dos manatins, se inspirou em Oviedo. Gómara foi posteriormente traduzido por vários outros autores, nomeadamente por Laet, ainda que este tenha excluído da sua descrição a história do manatim Matto, provavelmente por não a considerar fidedigna (Barrera-Osorio, 2012, p. 326-327). Na verdade, muito da informação observada e descrita sobre manatins e outros animais aquáticos apenas parcialmente passou para os círculos europeus da história e filosofia natural modernas (Brito, 2018), fosse por opção do tradutor ou escolha do autor, por falta de acesso a algumas publicações, ou por incongruências na descrição à qual não se atribuía veracidade. Independentemente do motivo, muito ficou por contar e conhecer sobre a fauna tropical aquática das Américas, e só recentemente alguma dessa informação começou a ser recuperada pela mais recente historiografia em história moderna da história natural ou em história ambiental (e.g. Brito, 2016). Matto voltou a surgir na obra "Jardín de Flores Curiosas" de Torquemada, segundo Durand (1950, p. 28, 38-41), um historiador particularmente apaixonado pelo inverossímil e pelo insólito.

Inverossímil para alguns autores, credível para outros, a história do manatim domesticado (Figura 4) indica que as pessoas daquela tribo viam no espírito pacífico de Matto o refinado cumprimento das melhores regras de conduta. ${ }^{11}$ Ele torna-se, à semelhança do golfinho que transportou o grego Arion, uma figura digna de entrar nas fábulas e epopeias humanas (Durand, 1950, p. 30). Mostra-nos como pessoas de diferentes origens culturais interagiam de formas distintas com o animal, confrontado o indígena com o europeu, e colocando neste último uma das causas para o desaparecimento do animal do seio da feliz comunidade "humana-animal" em que vivia.

Porém, mais do que uma romantização do ameríndio e das suas relações com a natureza, esse relato parece mostrar-nos que a domesticação da vida natural raramente é conseguida ou, pelo menos, nunca na totalidade. Essa tentativa humana de controlo é ainda mais difícil com animais aquáticos que vivem num ambiente tridimensional e muito diferente da realidade terrestre. Esses animais migram, deslocam-se, escondem-se, tornam-se mais elusivos, alteram comportamentos e podem até mudar a sua zona de ocupação. Em consequência dessas mudanças - muitas vezes impostas pela presença humana -, as sociedades dependentes de certos tipos de animais podem deslocar-se de acordo com essas alterações mais ou menos naturais. Os ecossistemas são redes complexas que envolvem todos os seres que nele habitam e dele dependem, assim como todas 


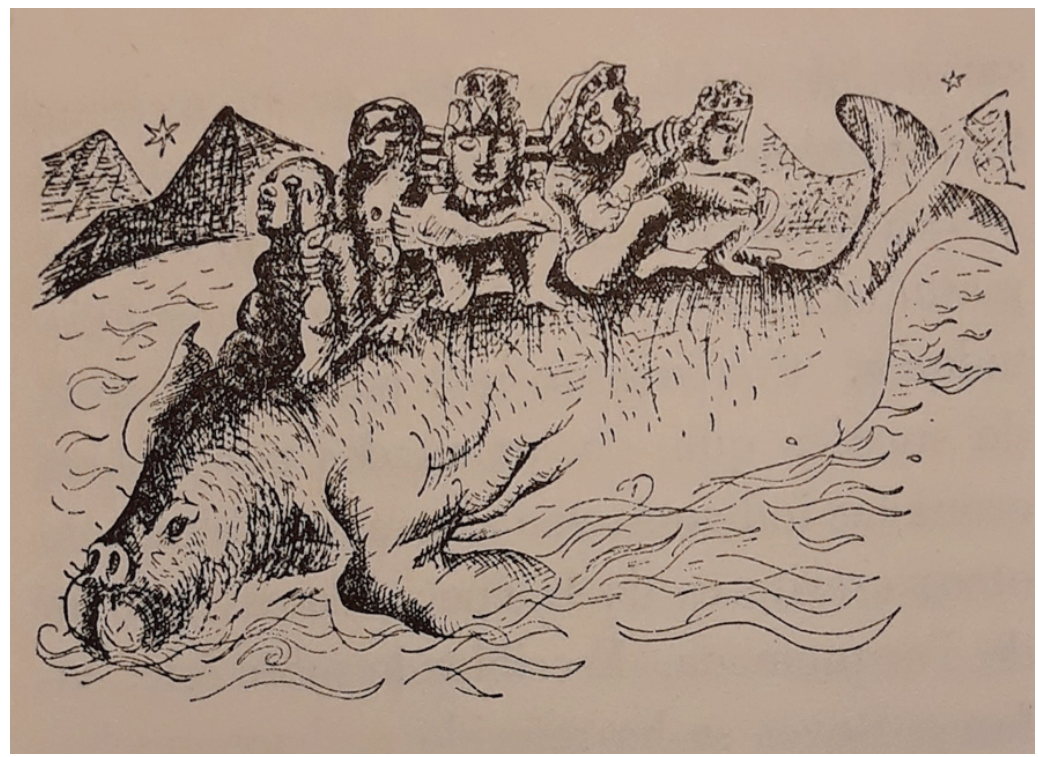

Figura 4 - Ilustração de Elvira Gascon, na obra de Durand (1950), representando a cena do magnífico manatim a transportar pessoas da tribo do cacique Caramatexi.

as ligações entre si. E essa teia de vida não conhece barreiras, mesmo incluindo humanos que historicamente se organizam por padrões de vida limitados por Estados-nação e por todo tipo de fronteiras - físicas, mentais e epistemológicas - que lhes são impostas (Rangarajan, 2011, p. 27-30).

Os manatins mantiveram o seu papel híbrido - pragmático e simbólico nos rios e águas costeiras onde viviam, e uma relação de grande proximidade com os humanos. Servem, por esses motivos, como caso de estudo a ser explorado, ficando ainda patente o efeito da agência da natureza, neste caso, a agência das águas dos rios ${ }^{12}$ e dos manatins sobre a vida e algumas das atividades humanas. Conhecendo os ritmos próprios da natureza, seria possível para as pessoas adaptar-se e utilizá-los em seu proveito. Não conhecendo, ou não compreendendo os acontecimentos naturais, não restava outra possibilidade que não se sujeitar a eles. Neste caso, o que o rio trazia, o rio levava de volta.

Estes peixes [manatins] pela maior parte se acham em alguns rios, ou baías desta costa [Santa Cruz, Brasil], principalmente onde algum ribeiro ou regato se mete na água salgada são mais certos: porque botam o focinho de fora e pacem as 
ervas que se criam em semelhantes partes e também comem as folhas de umas árvores a que chamam mangues, de que há grande quantidade ao longo dos mesmos rios. Os moradores da terra os matam com arpões e também em pesqueiras costumam tomar alguns, porque vem com a enchente da maré aos tais lugares e com a vazante se tornam a ir para o mar de onde vieram. (Gândavo, [15501557]1980, cap. 8)

Vistos como um recurso alimentar e medicinal, como matéria-prima para utensílios, como elemento religioso ou mágico, até como amigo ou animal de estimação, os manatins mantiveram ativa a sua agência no decorrer de todo o seu percurso histórico de interações com as sociedades indígenas e coloniais. A sua presença, tal como a de todos os outros elementos não humanos deste mundo tropical, comum na vida diária de tribos indígenas das Caraíbas e América do Sul, foi incorporada na vida dos europeus localmente, mas também na Europa. Tal acontecia mediante contacto direto e conhecimento empírico, ou por via de comunicações económicas ou científicas transatlânticas que faziam a informação chegar à Europa. O estabelecimento das relações humanas - as existentes e as que se formaram a partir da época moderna - com a natureza dessa região foi-se desenvolvendo não em total oposição, mas numa ligação próxima entre as pessoas e as outras espécies (e.g. Cabral, 2015, p. 104105). Nesse contexto, os sistemas aquáticos podem desvendar momentos de protagonismo de povos indígenas (Almeida; Kater, 2017) nas Américas na época pré-colombiana e moderna, bem como situações de protagonismo dos próprios animais.

Os rios representam fisicamente, mas também metaforicamente, sistemas de confluência nas interações entre pessoas diferentes, e entre pessoas e animais, ou ainda, num sentido mais lato, entre pessoas e a natureza. São verdadeiras zonas de agregação - de pessoas, de animais, de recursos e de possibilidades. São ainda vias de comunicação, zonas de viagem e conexão entre partes geográficas, e constituem um modo de transferência e de movimento de pessoas e de elementos naturais. Mas, tal como a maioria das situações de convergência entre humanos e o mundo não humano (e.g. Denning, 1980), verificam-se situações de divergência entre essas realidades ambivalentes. É algo comum a muitos sistemas ecológicos e humanos oceânicos, costeiros e fluviais espalhados pelo mundo, uma história de contradição na forma como as pessoas se relacionam e utilizam esses ecossistemas variados e plurais. Os rios, assim como outros elementos monumentais das paisagens naturais - ilhas (e.g. Denning, 1980), cascatas (e.g. Almeida; Kater, 2017), zonas costeiras, 
serras e florestas (e.g. Vadjunec et al., 2012) -, são cruzamentos espaciais que formam pontos de contacto e zonas de aglomeração de histórias e de construção da história.

Há assim uma história que não é apenas azul mas também castanha (Gillis; Torma, 2015, p. 1-3), porque inclui mar, rio e zonas de transição. É uma história ambiental marinha que contribui para uma apreensão e compreensão integrada dos sistemas ecológicos e humanos ao longo do tempo e em diferentes contextos históricos e culturais. Ainda que esta história não deixe suficientes vestígios escritos ou materiais, é possível reconstruí-la com ajuda de metodologias das diferentes disciplinas das humanidades (Gillis; Torma, 2015). Esses mesmos autores citam no fim do seu capítulo (p. 11) David Helvarg (2001, p. 245): “we love the ocean, we use the ocean, but we don't think enough about the ocean". Da mesma forma não pensamos o suficiente sobre os rios, as águas de transição, as zonas costeiras, nem tampouco sobre os manatins, as tartarugas, os tubarões e toda uma miríade de elementos de fauna e flora que habitam esses ecossistemas. Ecossistemas e elementos vivos dos quais dependemos e aos quais nos habituámos. O processo em prol de uma vida humana sustentável na Terra é agora uma inevitabilidade, e o processo histórico de trazer à tona da água esses animais, agentes ativos na criação do nosso passado comum, será um dos suportes para a nossa vida futura neste planeta.

\section{REFERENNCIAS}

ACOSTA, José de. Historia natural y moral de las Índias. Sevilla: Casa de Juan de Léon, 1590.

ALMEIDA, Fernando O.; KATER, Thiago. As cachoeiras como bolsões de histórias dos grupos indígenas das terras baixas sul-americanas. Revista Brasileira de História, São Paulo: Anpuh, v. 37, n. 74, p. 39-67, 2017.

ANCHIETA, Joseph. Capitania de S. Vicente. Rio de Janeiro: Imprensa Nacional, 1946. (Colecção Brasileira de Divulgação, Série IV, História, n. 3).

BARRERA-OSORIO, Antonio. Translating Facts: From Stories to Observations in the Work of Seventeenth-Century Dutch Translators of Spanish Books. In: COOK, Harold J.; DUPRE, Sven (ed.). Translating Knowledge in the Early Modern Low Countries. Wien: Lit Verlag, 2012. p. 317-332.

BARRERE, Pierre. Nouvelle Relation de la France Equinoxiale, Contenant la description des côtes de la Guiane; de'Isle de Cayenne; le commerce de cette colonie; les divers changemens arrivés dans ce Pays; \& les Moeurs \& Coûtumes des différens peuples 
sauvages qui l'habitent. Paris, 1743. Disponível em JCB Archive of Early American Images: https://jcb.lunaimaging.com/luna/servlet/s/5z74ig.

BLACKBOURN, David. "Time is a Violent Torrent": Constructing and Reconstructing Rivers in Modern Germany History. In: MAUCH, Christof; ZELLER, Thomas (ed.). Rivers in History: Perspectives on Waterways in Europe and North America. Philadelphia, MA: Penn State University Press, 2008a. p. 11-25.

BLACKBOURN, David. The Conquest of Nature: Water, Landscape, and the Making of Modern Germany. New York: Norton, 2008b.

BRADLEY, Richard. The Passage of Arms: An Archaeological Analysis of Prehistoric Hoards and Votive Deposits. Cambridge: Cambridge University Press, 1990.

BRITO, Cristina. New Science From Old News: Sea Monsters in the Early Modern Portuguese Production and Transfer of Knowledge About the Natural World. Lisboa: Escola de Mar, 2016. (Scientia et Historia, n. 1).

BRITO, Cristina. Connected Margins and Disconnected Knowledge: Exotic Marine Mammals in the Making of Early Modern European Natural History. In: POLÓNIA, Amélia; BRACHT, Fabiano; CONCEIÇÃO, Gisele C. da; PALMA, Monique (ed.). Cross-Cultural Exchange and the Circulation of Knowledge in the First Global Age. Porto: CITCEM: Afrontamento, 2018. v. 1, p. 106-132.

CABRAL, Diogo de Carvalho. Into the Bowels of Tropical Earth: Leaf-Cutting Ants and the Colonial Making of Agrarian Brazil. Journal of Historical Geography, Amsterdam: Elsevier, v. 50, p. 92-105, 2015.

CAMENIETZKI, Carlos Ziller; ZERON, Carlos Alberto. Quem conta um conto aumenta um ponto: o mito do Ipupiara, a natureza Americana e as narrativas da colonização do Brasil. Revista de Indias, Madrid, v. 60, n. 218, p. 111-134, 2000.

COATES, Peter. A Story of Six Rivers: History, Culture and Ecology. London: Reaktion Books, 2013.

DENNING, Greg. Islands and Beaches: Discourse on a Silent Land, Marquesas 17741880. Honolulu: The University Press of Hawaii, 1980.

DURAND, José. Ocaso de Sirenas: Manaties en el siglo XVI. México: Tezontle, 1950. FERREIRA, Óscar; MATIAS, Ana. Portugal. In: PRANZINI, Enzo; WILLIAMS, Allan (ed.). Coastal Erosion and Protection in Europe. London: Routledge, 2013. p. 278-293.

GALVÃO, António. Tratado dos Descobrimentos. [1573]. Lisboa: Publicações Alfa, 1989. (Biblioteca da Expansão Portuguesa, n. 13).

GÂNDAVO, Pêro de Magalhães. Tratado da terra do Brasil; História da Província Santa Cruz. [1550-1557]. Belo Horizonte: Itatiaia; São Paulo: Edusp, 1980.

GILLIS, John; TORMA, Francisca. Introduction. In: GILLIS, John; TORMA, Franziska (ed.). Fluid Frontiers: New Currents in Marine Environmental History. Cambridge: The White Horse Press, 2015. 
GÓMARA, Francisco Lopéz de. Histoire Generalle des Indes Occidentales, et Terres neuves qui iusques à presente ont esté descouvertes. Composse en Espagnol par François Lopez de Gomara, \& traduite en François par le S. de Genille Mart. Fumée. Paris, 1605.

GÓMARA, Francisco Lopéz de. Historia general de las Indias. Barcelona: Linkgua, 2008.

GUDGER, Edward W. On the Use of the Sucking-Fish for Catching Fish and Turtles: Studies in Echeneis or Remora, II. The American Naturalist, v. 53, n. 627, p. 289$311,1919$.

HEATON, Harry Clifton (ed.). The Discovery of the Amazon According to the Account of Friar Gaspar de Carvajal and Other Documents, as Published With an Introduction by José Toribio Medina. New York: American Geographical Society, 1934.

HELVARG, David. Blue Frontier: Saving America's living seas. New York: Freeman, 2001.

LABAT, Jean Baptiste. Nouveau voyage aux isles de l'Amerique: contenant l'histoire naturelle de ces pays, l'origine, les mœurs, la religion \& le gouvernement des habitans anciens \& modernes. Les guerres \& les evenemen. A Paris: Rue S. Jacques, chez Pierre-François Giffart, près la ruë des Mathurins, à l'image Sainte Therese, 1722 [1663-1738]. Disponível em: https://archive.org/details/ouveauvoyageaux09laba.

LEITE, Bruno M. B. Animalia exotica \& mirabilia. Os animais brasileiros na cultura europeia da época moderna de Thevet a Redi. In: KURY, Lorelai (org.). Representações da fauna no Brasil: séculos XVI-XX. Rio de Janeiro: Andrea Jakobsson, 2014. p. 40-81.

LOPES, Marília dos S. Coisas maravilhosas e até agora nunca vistas: para uma iconografia dos Descobrimentos. Lisboa: Quetzal, 1998.

LOVELAND, Franklin O. Tapirs and Manatees: Cosmological Categories and Social Process Among Rama Indians in Eastern Nicaragua. In: HELMS, Mary W.; LOVELAND, Franklin O. (ed.). Frontier Adaptations in Lower Central America. Philadelphia, PA: Institute for the Study of Human Issue, 1976. p. 67-92.

MANGOR, Karsten. Human Causes of Coastal Erosion. [S. 1.], 2018. Disponível em: http://www.coastalwiki.org/wiki/Human_causes_of_coastal_erosion. Acesso em: 26 jun. 2018.

MAUCH, Christof; ZELLER, Thomas. Rivers in History and Historiography: An Introduction. In: MAUCH, Christof; ZELLER, Thomas (ed.). Rivers in History: Perspectives on Waterways in Europe and North America. Philadelphia, PA: Penn State University Press, 2008. p. 1-10.

MCCULLY, Patrick. Silenced Rivers: The Ecology and Politics of Large Dams. London: Zed Books, 2001.

NATIONAL RESEARCH COUNCIL. Managing Coastal Erosion. Washington, DC: The National Academies Press, 1990. 
PAPAVERO, Nelson; TEIXEIRA, Dante. Zoonímia tupi nos escritos quinhentistas europeus. São Paulo: NEHiLP/FFLCH/USP, 2014.

PHILOPONUS, Honorius. Nova typis transacta navigatio: Novi Orbis Indiæ Occidentalis. Linz, 1621. Disponível em: https://archive.org/details/novatypistransac00phil_0; imagem disponível em JCB Archive of Early American Images: https:// jcb.lunaimaging.com/luna/servlet/s/k61zy0.

RANGARAJAN, Mahesh. Nations, Nature, and Environmental History. RCC Perspectives - The Future of Environmental History: Needs and Opportunities, Munich: Rachel Carson Center, v. 3, p. 27-30, 2011.

VADJUNEC, Jacqueline M.; SCHMINK, Marianne; GREINER, Alyson L. New Amazonian Geographies: Emerging Identities and Landscapes. In: VADJUNEC, Jacqueline M.; SCHMINK, Marianne (ed.). Amazonian Geographies: Emerging Identities and Landscapes. London: Routledge, 2012. p. 1-20.

VASCONCELLOS, Simão de. Noticias curiosas, e necessarias das cousas do Brasil. Livro I. Lisboa: Na officina de Ioam de Costa, 1668.

VERÍSSIMO, José. A Pesca na Amazônia. Belém: Ed. UFPA, 1970.

VIEIRA, Nina; BRITO, Cristina. Brazilian Manatees (Re)Discovered: Early Modern Accounts Reflecting the Overexploitation of Aquatic Resources and the Emergence of Conservation Concerns. International Journal of Maritime History, v. 29, n. 3, p. 513-528, 2017.

WORSTER, Donald. Rivers of Empire: Water, Aridity, and the Growth of the American West. Oxford: Oxford University Press, 1992.

ZIMMERMANN, Eberhard. Tabula Mundi Geographico Zoologica sistens Quadrupeds hueusque notos sedibusque suis adscriptos. Leiden: T. Haak \& Soc, 1777. Disponível em JCB Map Collection: https://jcb.lunaimaging.com/luna/servlet/s/050i21.

\section{NOTAS}

${ }^{1}$ Este trabalho foi desenvolvido numa estadia na John Carter Brown Library at Brown University (2018) como investigadora convidada, pelo que agradeço ao seu diretor Neil Safier, ao staff e aos colegas que me proporcionaram um ambiente de partilha único para o desenvolvimento da minha pesquisa. Agradeço ainda a Celso Aleixo Pinto, APA - Agência Portuguesa do Ambiente, I.P., pela sua colaboração com a Linha de Investigação "História Ambiental e o Mar" do CHAM - Centro de Humanidades (NOVA FCSH) no âmbito do tratamento e análise dos dados geográficos (mapa da Figura 1). Agradeço igualmente a Catarina Garcia, Nina Vieira, Patrícia Carvalho e Carla A. Pinto, colegas do CHAM pelo apoio e dedicação ao trabalho de investigação sobre o mar na época moderna. Este trabalho insere-se no projeto H2020 MSCA-RISE [777998 "CONCHA-The construction of early modern global Cities and oceanic networks in the Atlantic: An approach via Ocean's Cultural Heritage"], na Cátedra UNESCO “The Oceans' Cultural Heritage” (FCSH, 
Universidade NOVA de Lisboa) e foi apoiado pelo projeto estratégico do CHAM (FCSH, NOVA, UAc) financiado pela FCT (UID/HIS/04666/2013). Este trabalho é também financiado por fundos nacionais por intermédio da FCT - Fundação para a Ciência e a Tecnologia, I.P., no âmbito da celebração do contrato-programa previsto nos números 4, 5 e 6 do art. 23 do D.L. no 57/2016, de 29 de agosto, alterado pela Lei n 57/2017, de 19 de julho.

${ }^{2}$ A título de exemplo, uma passagem que remete para a ferocidade dos tubarões e as relações das pessoas com esse peixe nas Índias Ocidentais do século XVIII: "No mesmo dia os nossos marinheiros tomaram um tubarão que por dois ou três dias não tinha saído de perto do navio; foi difícil coloca-lo a bordo, ele tinha mais de dez pés de comprimento; é o mesmo peixe que chamamos em la Rochelle um cão do mar, mas esses que eu tinha visto não tinham mais de dois pés de comprido [...] ele está armado de três filas de dentes fortes, agudos e afiados; é um animal voraz, ousado e perigoso" (LABAT, 1722, p. 45-46). Os tubarões, tal como os manatins, são (re)significados de forma semelhante por diferentes naturalistas, humanistas e missionários, mesmo que com bastante tempo de diferença entre as suas publicações. O medo é uma constante no caso dos tubarões. A curiosidade naturalista, o interesse utilitário e o valor comercial aparecem de modo transversal nas passagens descritivas sobre manatins. O olhar europeu sobre esses animais tropicais parece ser igual.

${ }^{3}$ Transcrição da passagem de Cristóvão Colombo, conforme aparece no livro de José Durand (DURAND, 1950, p. 22): "El día pasado, cuando el Almirante iba al río del Oro, dijo que vido três serenas que salieron bien alto de la mar, pero no eran tan hermosas como laspintan, que en alguna manera tenían forma de hombre en la cara. Dijo también que otras veces vido algunas en Guinea, en la costa de Manegueta".

${ }^{4}$ Apenas no Brasil coincidem as áreas de distribuição das espécies T. manatus and T. inunguis; a primeira ocorre em meio costeiro, podendo entrar em embocaduras de rio, mangais e estuários, e a segunda é exclusivamente de águas interiores, ocorrendo no rio Amazonas e possivelmente também no Orinoco. Em tempos passados, de maior abundância de populações e indivíduos, é muito provável que existissem áreas de sobreposição na distribuição de ambas as espécies nas zonas de transição entre os rios e o mar.

${ }^{5}$ The IUCN Red List of Threatened Species, Version 2017-3, http://www.iucnredlist.org, downloaded on 27 June 2018.

${ }^{6}$ As descrições do manatim e outras espécies de mamíferos marinhos e animais aquáticos revelam muito do conhecimento empírico sobre a natureza tropical e a fauna local. No entanto, eram muitas vezes confundidas ou usadas como a origem para crenças locais; deles surgiam monstros aquáticos, homens-marinhos, seres híbridos e diversas mitologias indígenas aquáticas. As narrativas dos cronistas para a América Portuguesa são diversas (e.g. CAMENIETZKI; ZERON, 2000), e vários autores se têm dedicado à discussão dessas temáticas a partir de múltiplas perspetivas (e.g. CAMENIETZKI; ZERON, 2000; LEITE, 2014; PAPAVERO; TEIXEIRA, 2014; BRITO, 2018).

${ }^{7}$ São vários os documentos e as fontes que dão conta de uma diminuição significativa do número de manatins no Brasil colonial, a partir de meados do século XVIII. Ver: VIEIRA; BRITO, 2017. 
${ }^{8} \mathrm{O}$ padre José de Acosta referia que aceitava, mas não sem dúvidas, consumir a carne de manatim às sextas-feiras porque esse era um verdadeiro animal que tinha crias e as amamentava ainda que vivesse dentro de água. Era normalmente consumido como peixe nas ilhas de Cuba, Santo Domingo, Porto Rico e Jamaica (HEATON, 1934, p. 329): "Nas ilhas que chamam de Barlavento [...] há aquilo que chamam manatim, um estranho género de pescado, se se pode chamar pescado a um animal que pare os seus filhos vivos, e tem tetas, e com leite os cria, e alimenta-se de erva no campo; mas com efeito habita de ordinário a água, e por isso o comem por pescado, ainda que no Santo Domingo quando o comi numa sexta-feira, quase tinha escrúpulos, não tanto pelo feito, como porque na cor e sabor não parecia senão com talhadas de vitela" (ACOSTA, 1590, p. 7).

${ }^{9}$ Os Taíno - considerados pescadores exímios - eram, no momento da chegada dos Europeus às Caraíbas no fim do século XV, um dos povos indígenas que ocupavam várias das ilhas dessa região. À chegada de Cristóvão Colombo, em 1492, existiam na ilha denominada Hispaniola cinco chefias e territórios Taíno, cada qual liderado por um cacique (chefe).

${ }^{10}$ Marília Lopes usa esta mesma imagem para ilustrar o conceito de fantasia associada às descobertas e explorações europeias sobre o mundo natural das Américas: "Os eruditos europeus alegram-se ao ouvir contar sobre as novidades das terras recentemente achadas: animais, peixes, aves, árvores, plantas e frutos nunca vistos. [...] [Mas] A arte gráfica recorre também a uma outra linguagem: a da fantasia. Seguindo os relatos de seres fantásticos e extraordinários dos Livros de Maravilhas, os artistas dão lugar à estranheza e novidade desenhando, por exemplo, um peixe, ou um anfíbio, de enormes dimensões capaz de transportar cinco homens no seu dorso" (LOPES, 1998, p. 74-75).

${ }^{11}$ A palavra usada pelo autor neste contexto é "urbanidad", no sentido em que se refere a um grupo de pessoas, ou a uma urbe, vivendo num ambiente comum de convivência e respeito mútuo.

${ }^{12}$ Agência do rio (ou do animal) funciona aqui na perspetiva mais elástica do conceito que Peter Coates (COATES, 2013, p. 7-31) nos apresenta, aquela em que existe uma agência não reflexiva que emerge da capacidade de produzir ou condicionar determinados resultados. Na visão desse autor, na qual nos revimos, os atores envolvidos não têm que ser racionais, nem tampouco inteligentes, apenas efetivos. Mais, diz-nos esse autor, se possuir vontade, lógica e um sentido de direção podem ser considerados atributos essenciais de agência, então, também nessa perspetiva os rios se qualificam como agentes ativos.

Artigo recebido em 28 de junho de 2018.

Aprovado em 12 de maio de 2019. 